AIAA-2000-3562

\title{
IMPROVED TENSILE ADHESION SPECIMENS FOR HIGH STRENGTH EPOXY SYSTEMS IN AEROSPACE APPLICATIONS
}

\author{
M. Reed Haddock \\ Thiokol Propulsion, a Division of Cordant Technologies, Inc. \\ Brigham City, Utah \\ Michael L. McLennan \\ Thiokol Propulsion, a Division of Cordant Technologies, Inc. \\ Brigham City, Utah
}

\begin{abstract}
$\underline{\text { Abstract }}$
An improved tensile adhesion button has been designed and tested that results in higher measured tensile adhesion strength while providing increased capability for testing high strength epoxy adhesive systems. The best attributes of two well-established tensile button designs were combined and refined into an optimized tensile button. The most significant design change to the tensile button was to improve alignment of the bonded tensile button specimens during tensile testing by changing the interface between the tensile button and the tensile test machine. The established or old button design uses a test fixture that pulls from a gronved annulus or anvil head while the new button design pulls from a threaded hole in the centerline of the button (see Figure 1). Finite element (FE) analysis showed that asymmetric loading of the established anvil head tensile button significantly increases the stress concentration in the adhesive, causing failure at lower tensile test loads. The new tensile button was designed to eliminate asymmetric loading and eliminate misalignment sensitivity. Enhanced alignment resulted in improved tensile adhesion strength measurement up to $13.8 \mathrm{MPa}(2000 \mathrm{psi})$ over the established button design. Another design change increased the capability of the button by increasing the threaded hole diameter allowing it to test high strength epoxy systems up to 85 MPa (>12,000 psi). The improved tensile button can be used in button-to-button or button-to-panel configurations.
\end{abstract}

Copyright $\odot 2000$ by Thiokol Propulsion, a division of Cordant Technologies, Inc. Published by the American Institute of Aeronautics and Astronautics. Inc. with permission.
Introduction

An important epoxy adhesive material property needed in structural analysis is tensile adhesion strength. Various tensile specimen contigurations have been employed to define tensile adhesion strength of adhesives. Two tensile configurations are button-tobutton and button-to-panel. The button-to-button configuration uses a pair of cylindrical metal buttons bonded together. The button-to-panel configuration uses a flat panel of sufficient thickness allowing space for several buttons to be bonded to it. Adherends are processed like the intended structure through bond surface preparation processes (i.e., cleaning, surface finish treatments and priming). Following surface preparation, adhesive is applied to the prepared bond surfaces and the adherends are joined together using a spacer to lociate the button halves and space the button bond surfaces. Tooling is used to seat the button halves in the spacer during adhesive cure. Typical tensile button contigurations are shown in Figure I.

\section{Discussion}

A significant difference in tensile adhesion strength values, observed between anvil head button-to-button and beveled button-to-panel specimens, prompted some work to understand it. For the same epoxy adhesive, the old anvil head specimens failed at a lower stress than the old beveled button-to-panel specimens (Figure 1 depicts the different configurations and specimens).

Axisymmetric FE analysis with ABAQUS ${ }^{\mathrm{TM}} /$ Standard Version 5.8 predicted the anvil head button-to-button configuration had a lower stress concentration than the beveled button-to-panel configuration (see Figure 2). A high stress concentration should reduce the load 
capability, however, the panels failed at higher loads than the buttons.

G. P. Anderson ${ }^{1.2}$ showed experimentally and with analysis that improving alignment in the tensile testing of anvil head buttons increased failure loads and reduced variability. Axisymmetric analysis assumes a symmetric or perfectly aligned load so is unable to model misalignment. Therefore, elements that allow asymmetric loading $\left(\mathrm{CAXA}^{3}\right)$ were used to model misalignment or edge loading. Figure 3 shows that the stress concentration can increase dramatically with edge loading. Therefore, a design change that reduced edge loading should increase failure loads.

From a review of the two tensile button configurations, a hypothesis was formed that alignment during tensile testing was the critical factor. The hypothesis was based on the difference in how the tensile button attached to the universal test machine and its potential to affect tensile adhesion strength (see Figure 4). It was believed that attachment to the groove in the tensile button caused misalignment during testing and resulted in failure initiation at the edge of the button rather than at the center.

To alleviate the possibility of edge loading, the new design used a threaded hole in the center of the old tensile button. Instead of gripping the tensile button specimen in the universal test machine from the groove. the tensile button specimen would be gripped from a threaded hole (see Figure 1, New). Additionally, the groove in the tensile button was no longer needed and was removed. The groove did not influence the results and FEA models showed insignificant change in the adhesive's stress. Based on the structural analysis results, a couple of modifications were made to the existing button-to-button configuration to evaluate the threaded center-hole concept. A threaded center hole similar to the one in the beveled button was added to the anvil head buttons. One of the adhesives tested was a very high strength epoxy adhesive that caused the bolt in the universal test machine fixture (that threads into the tensile button $6 \mathrm{~mm}$ threaded hole) to fail occasionally. The threaded hole was increased in diameter (to $9 \mathrm{~mm}$ ) and depth to allow a larger bolt to withstand the high-strength capability of the TIGA 32 lepoxy adhesive. Tensile buttons with $6 \mathrm{~mm}$ and 9 mm threaded holes were also tested to ensure alignment was not affected by the larger diameter bolt.

\section{Results}

Tests were conducted to prove or disprove the alignment hypothesis. Initial tests involved modifying the old button-to-button configuration (anvil head button) by adding a $6 \mathrm{~mm}$ threaded hole (see Figure 1) to the center of each button half. Using EA913NA epoxy adhesive from Dexter Hysol, a number of anvil head and threaded anvil head buttons were prepared, bonded and cured through the same process and equipment at the same time. The tensile button specimens were tested in a universal test machine at the same temperatures and rates to provide a good comparison. The results of testing using EA913NA adhesive indicated an approximate $5 \mathrm{Mpa}(800 \mathrm{psi})$ increase when testing from the threaded hole rather than the groove or annulus (see Figure 5).

Next, testing was conducted using TIGA 321 epoxy adhesive to evaluate a larger threaded hole diameter (to address the thread shear issue). Results indicated statistically equivalent tensile adhesion strengths for both $6 \mathrm{~mm}$ and $9 \mathrm{~mm}$ threaded hole diameters (see Figure 6).

Tensile adhesion strength testing was then conducted to evaluate the elimination of the groove or annulus on center-pull specimens. Buttons were fabricated with and without the groove or annulus, bonded with TIGA 321 adhesive and tested. Elimination of the groove had no statistically significant effect on tensile adhesion strength (see Figure 7).

Finally, testing was conducted to evaluate the new tensile button design (large threaded center-hole, no groove) with a high strength adhesive, TIGA 321 , at various test temperatures. To support the test, a number of new (threaded cylinder) and old (anvil head) buttons were prepared, bonded and cured through the same process and equipment at the same time. Testing was conducted at various temperatures ranging from $-6.7^{\circ} \mathrm{C}$ $\left(20^{\circ} \mathrm{F}\right)$ to $82.2^{\circ} \mathrm{C}\left(180^{\circ} \mathrm{F}\right)$. The results confirmed a significant increase in tensile adhesion strength with the new buttons over the old anvil buttons. At $22.2^{\circ} \mathrm{C}(72$ ${ }^{\circ} \mathrm{F}$ ) test temperature, the strength was $10 \mathrm{MPa}$ higher when testing from the threaded hole rather than the groove (see Figure 8). 
Higher measured tensile adhesion strengths for the same adhesive were obtained when alignment of the tensile adhesion button specimens in the universal test machine was improved. Data suggests that alignment of tensile adhesion button specimens is improved when replacing the groove in the button with a threaded hole as the attach point to the universal test machine for a large temperature range. Increasing the threaded-hole size from $6 \mathrm{~mm}$ to $9 \mathrm{~mm}$ made had no statistically significant effect on tensile adhesion strength, but increased the capability of the button to test high sirength adhesives. Eliminating the annulus or groove in the previous tensile adhesion button design resulted in no statistically significant effect on tensile adhesion strength. $\underline{\text { References }}$

1. Anderson, G.P., DeVries, K.L. and Sharon, G., "Evaluation of Tensile Tests for Adhesive Bonds," Delamination and Debonding of Materials, ASTM STP 876, W.S. Johnson, Ed., American Society for Testing and materials, Philadelphia, 1985, pp. 115134.

2. Anderson, G.P., Chandapeta, S., and DeVries, K.L., "Effect of Removing Eccentricity from Button Tensile Adhesion Tests," Adhesively Bonded Joints: Testing, Analysis, and Design, ASTM STP981, W.S. Johnson, Ed., American Society for Testing and Materials, Philadelphia, 1988, pp.5-12.

3. Hibbitt, Karlsson \& Sorensen, Inc., "ABAQUS/Standard User's Manual," Version 5.8.

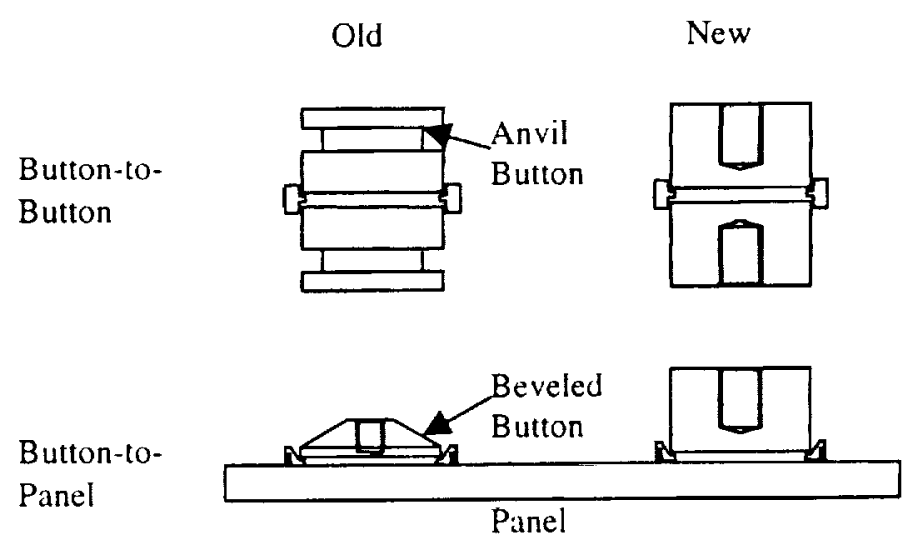

Figure 1 Cross-sectional views of old and new tensile button specimen configurations. 


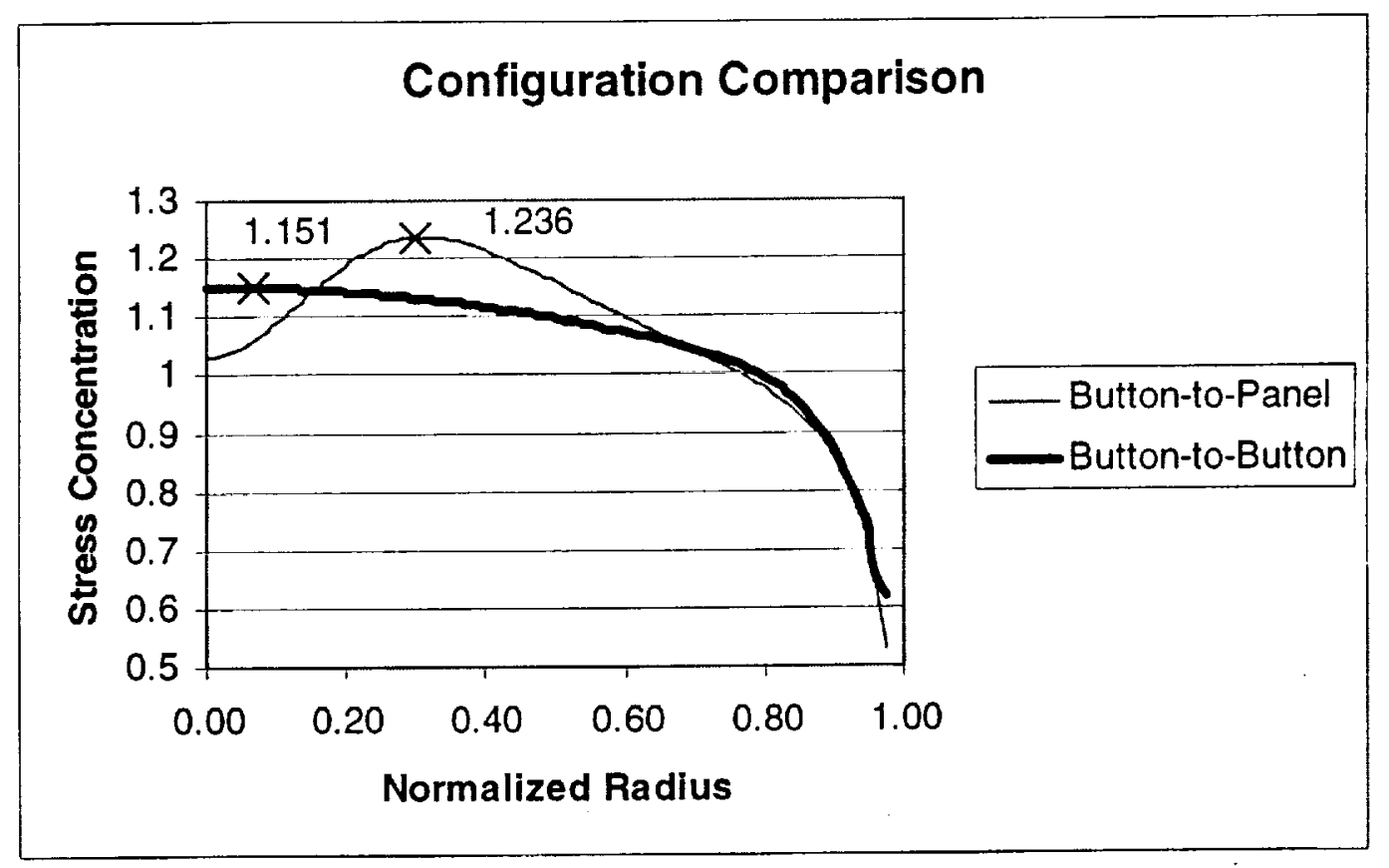

Figure 2 Structural comparison of tensile buttons.

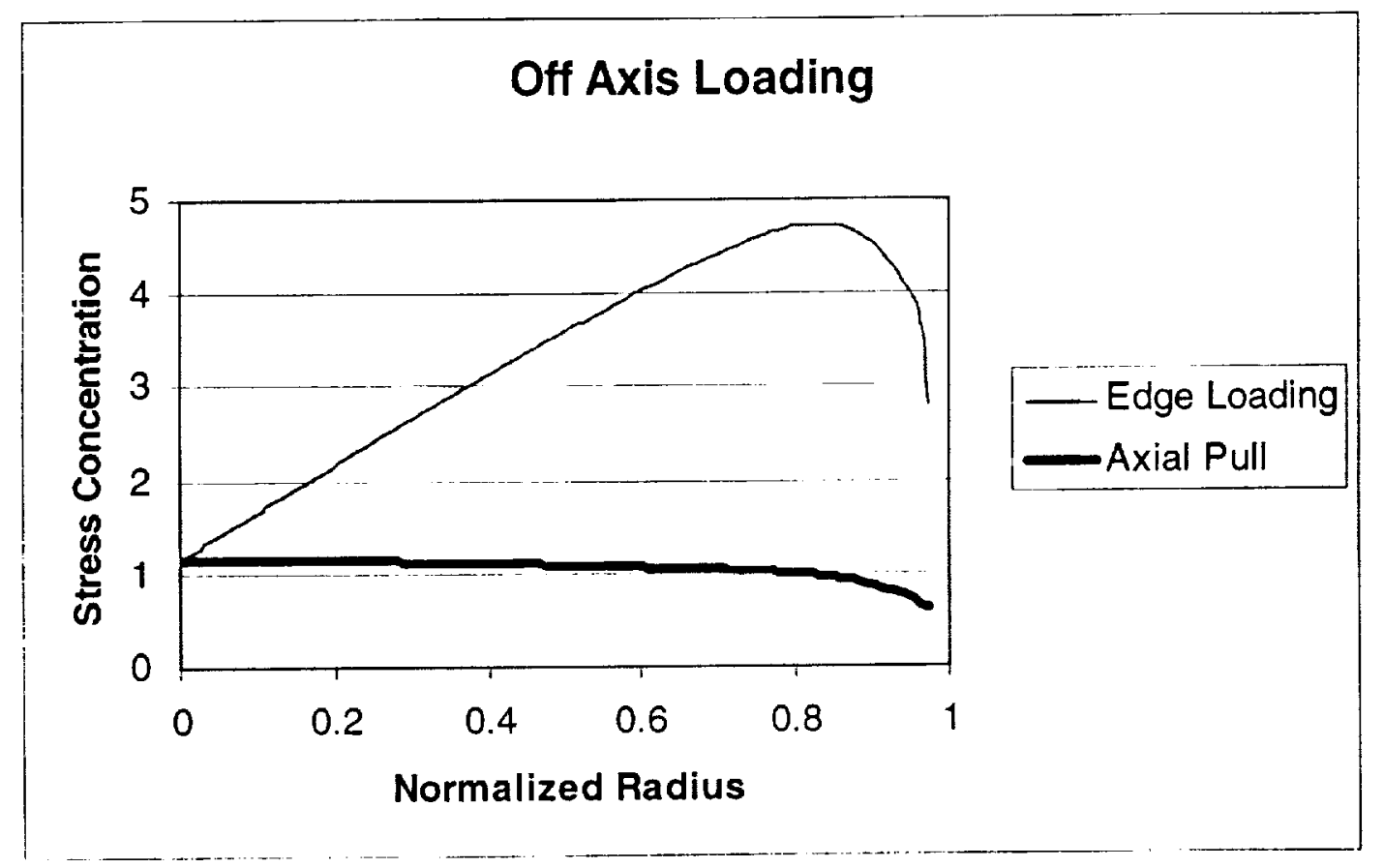

Figure 3 Edge loading comparison. 

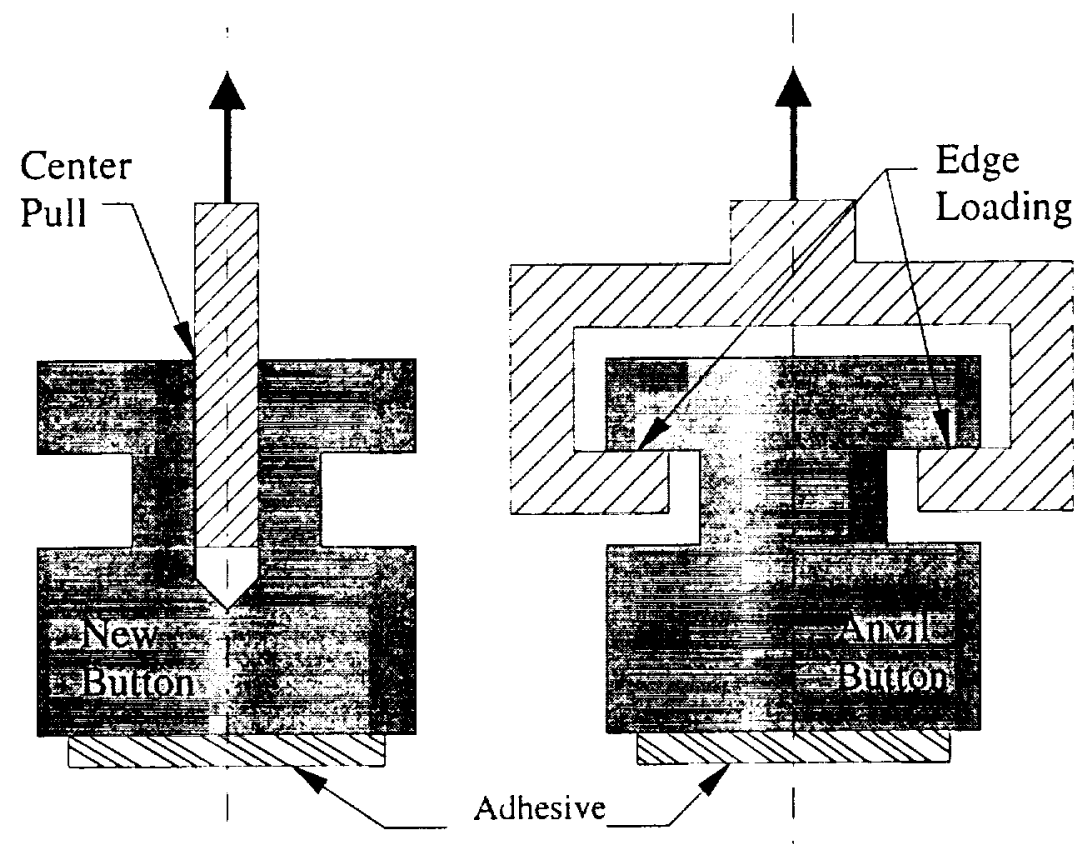

Figure 4 Attachment to universal test machine.

TENSILE ADHESION SPECIMEN CONFIGURATION COMPARISON EA913NA / SILANE / STEEL ( $1 \%$ or less volds)

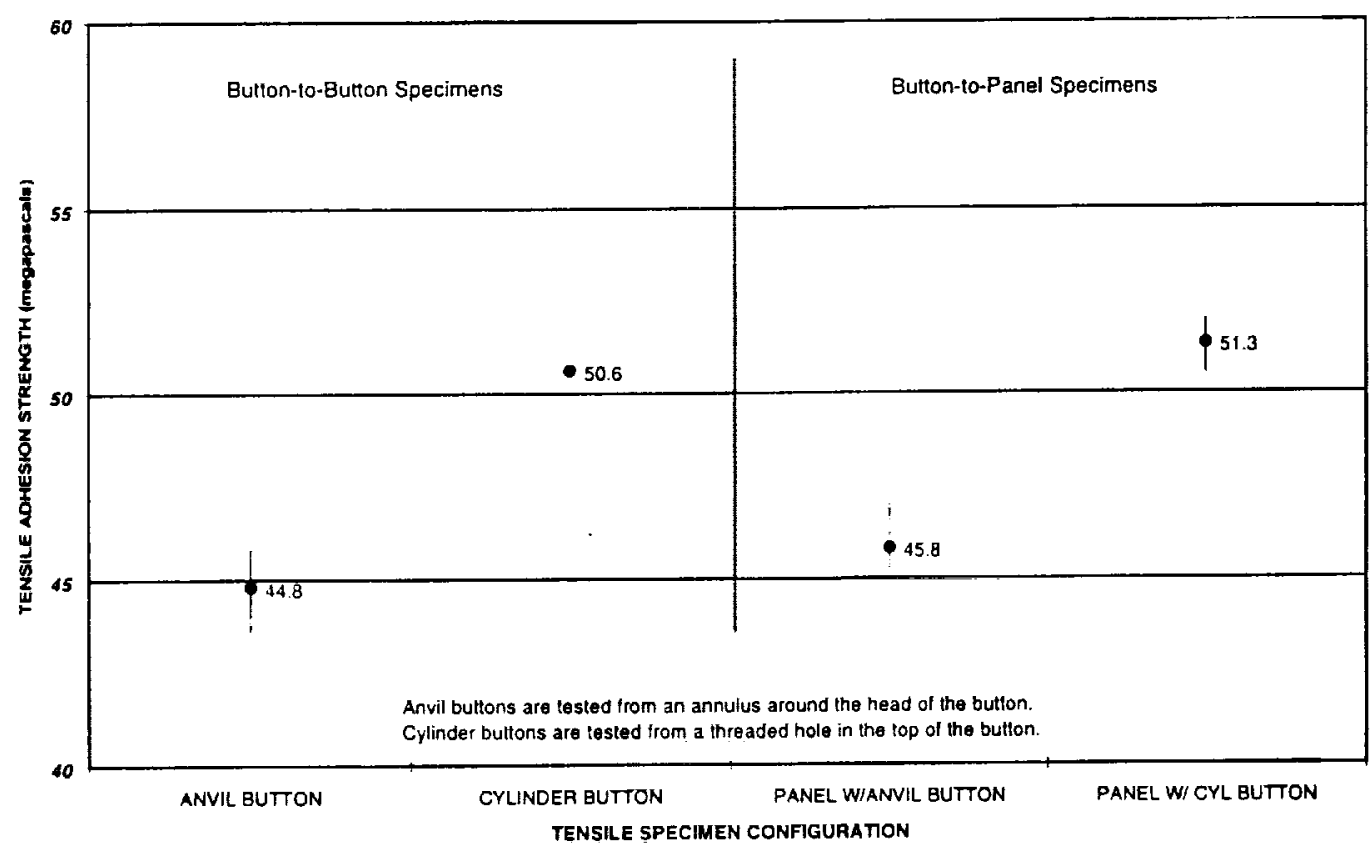

Figure 5 Comparison of tensile buttons tested from threaded hole and annulus. 
TENSILE STRENGTH OF THREADEO CYLINDER BUTTONS BONDED WITH TIGA 321

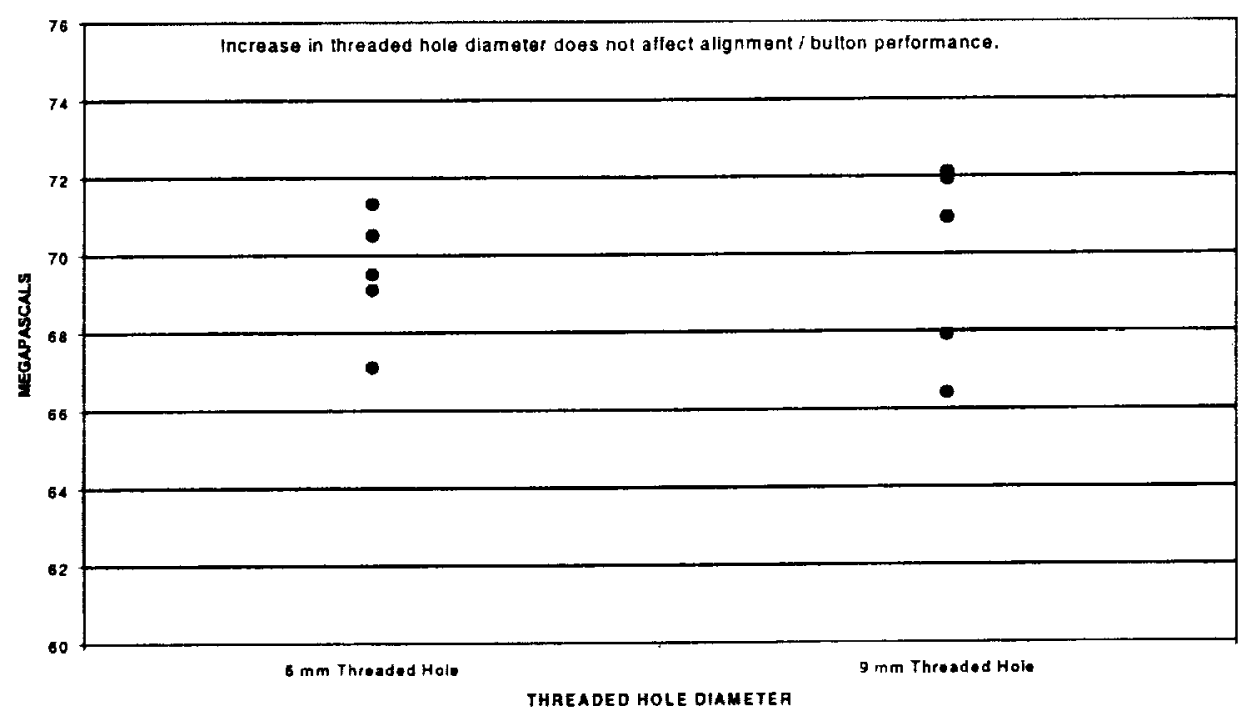

Figure 6 Threaded hole effect on alignment.

TENSILE ADHESION STRENGTH WITH TIGA 321

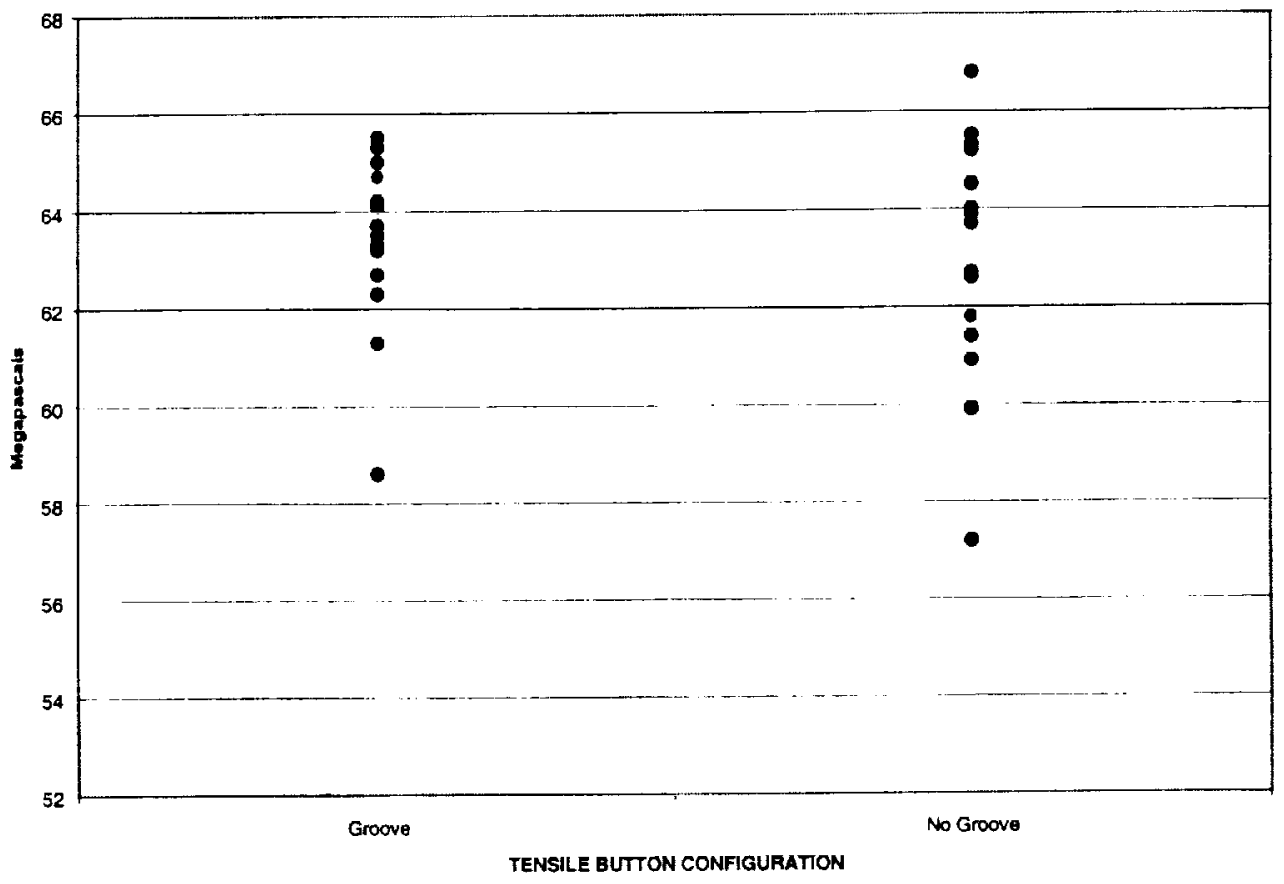

Figure 7 Groove elimination effect on tensile adhesion strength. 


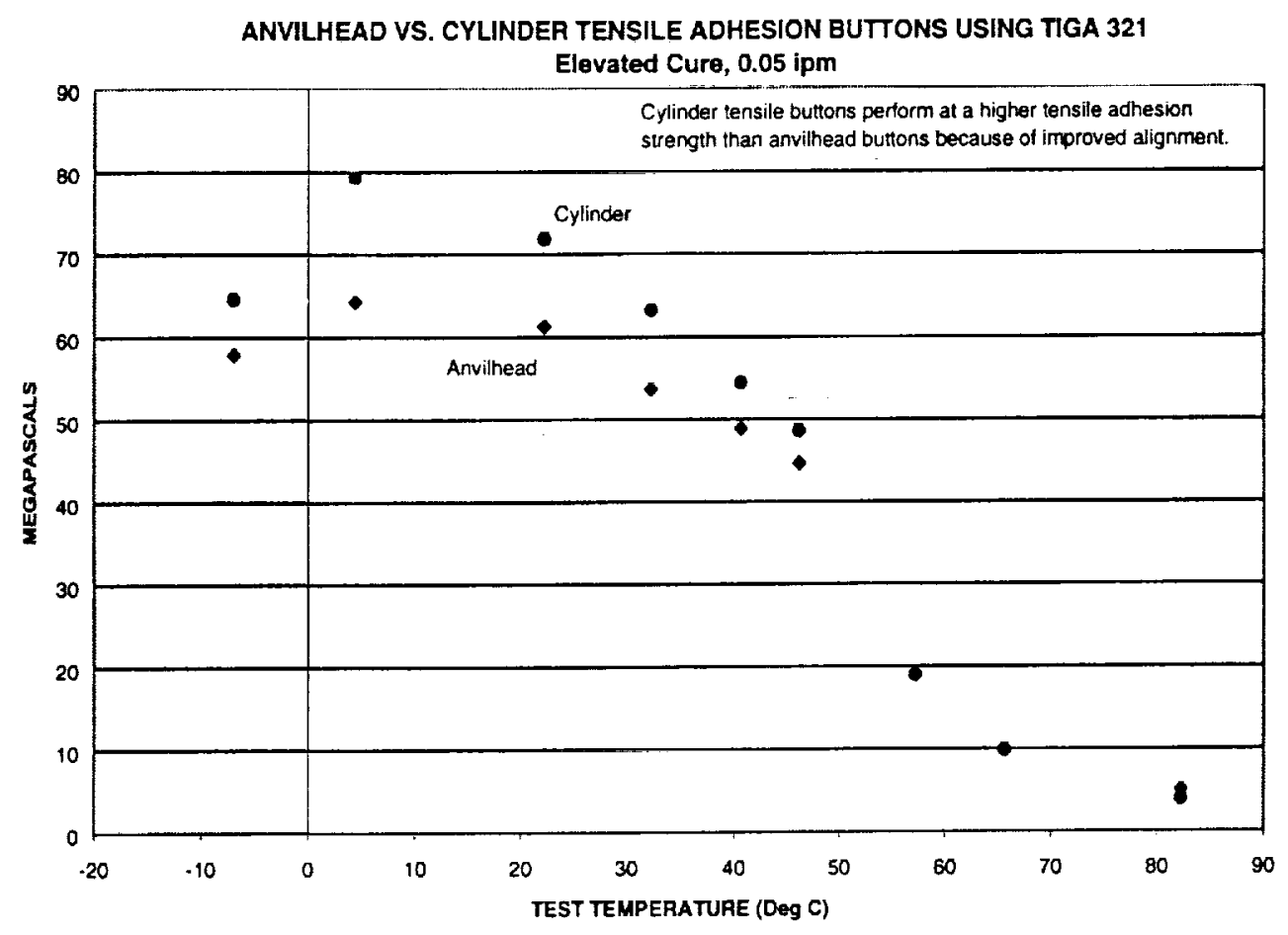

Figure 8 Comparison of tensile buttons bonded with TIGA-321. 